\title{
BACTERIOLOGICAL PROFILE OF VENTILATOR ASSOCIATED PNEUMONIA IN A TERTIARY CARE CENTRE OF DAKSHINA KANNADA DIST.
}

\author{
Sateesh K1, Sathya Anandam², Vidya Pai ${ }^{3}$
}

${ }^{1}$ Associate Professor, Department of Microbiology, Yenepoya Medical College, Deralakatte, Mangalore. ${ }^{2}$ Assistant Professor, Department of Microbiology, Yenepoya Medical College, Deralakatte, Mangalore. ${ }^{3}$ Professor, Department of Microbiology, Yenepoya Medical College, Deralakatte, Mangalore.

\section{ABSTRACT}

\section{BACKGROUND}

Mechanical ventilation can increase the risk of VAP $7-21$ times and 10\%-25\% of patients undergoing mechanical ventilation develop pneumonia. The aetiological agents of VAP vary with different patient populations and types of ICUs. Prompt administration of appropriate antibiotics seems to be the only intervention that alters outcome once the diagnosis is established.

\section{MATERIALS AND METHODS}

This is a descriptive study with seventy-four non-repetitive endotracheal aspirate from patients who were on mechanical ventilation for more than $48 \mathrm{hrs}$. and in whom ventilator associated pneumonia was suspected using modified CPIS score and quantitative culture was confirmed using modified two-fold dilution scheme. Kirby-Bauer disk diffusion method was adopted for antimicrobial susceptibility testing.

\section{RESULTS}

The most common isolate was pseudomonas aeruginosa (27\%) followed by Acinetobacter spp. (20.3\%), Klebsiella spp. (16.2\%) and E. coli (12\%). Among gram positive bacteria in our study, only Staphylococcus aureus (9.5\%) was isolated. Amikacin and levofloxacin were found to be better against non-fermenters; $10 \%$ were carbapenemase producers, MDR isolates were observed in enterobacteriaceae members. MRSA was found in $28.6 \%$.

\section{CONCLUSION}

In conclusion, the incidence of VAP and the prevalence of multidrug resistant microorganisms were quite high in our ICU setup. A local surveillance program at each centre is essential, as the knowledge of local resistant patterns is vital for selecting the appropriate agents for treating infections.

\section{KEYWORDS}

VAP, Gram Negative Isolates, MDR Pathogens, MRSA.

HOW TO CITE THIS ARTICLE: Sateesh K, Anandam S, Pai V. Bacteriological profile of ventilator associated pneumonia in a tertiary care centre of Dakshina Kannada dist. J. Evolution Med. Dent. Sci. 2017;6(80):5664-5667, DOI: 10.14260/jemds/2017/1228

\section{BACKGROUND}

Ventilator-associated pneumonia (VAP) is defined as pneumonia occurring more than 48 hours after the initiation of endotracheal intubation and mechanical ventilation (MV) including pneumonia developing even after extubation. ${ }^{1}$ Mechanical ventilation can increase the risk of VAP $7-21$ times and $10 \%$ - 25\% of patients undergoing mechanical ventilation develop pneumonia. ${ }^{2}$ It results in high mortality and morbidity, prolonged lengths of hospitalisation and also increased cost of hospitalisation. The mortality rates for VAP range from $20 \%$ to $75 \%$ according to the study population. ${ }^{3}$

Accurate data on aetiologic agents and the epidemiology of VAP are limited by the lack of a 'gold standard' for diagnosis. However, regardless of the diagnostic technique used, there have been dramatic variations in the distribution of pathogens and drug resistance patterns. Because early and

'Financial or Other Competing Interest': None.

Submission 22-08-2017, Peer Review 23-09-2017,

Acceptance 28-09-2017, Published 05-10-2017.

Corresponding Author:

Dr. Sathya Anandam,

Assistant Professor,

Department of Microbiology,

Yenepoya Medical College,

Deralakatte, Mangalore.

E-mail: sathyakims@yahoo.com

DOI: $10.14260 / j e m d s / 2017 / 1228$ appropriate antimicrobial therapy is an important goal in the setting of life-threatening infections, taking into account factors that modulate bacterial ecology and the susceptibility of causative organisms is crucial for optimal management.

Prompt administration of appropriate antibiotics seems to be the only intervention that alters outcome once the diagnosis is established. ${ }^{1}$ Microorganism responsible for VAP may differ according to the population of patients in the ICU, the duration of hospital and ICU stays, and the specific diagnostic methods used. The high rate of respiratory infections due to gram negative bacilli in this setting has been documented. Resistance rate of gram negative bacilli to penicillins, cephalosporins, Fluoroquinolones and aminoglycosides varies between hospitals, but is generally increasing. ${ }^{2}$

A number of studies from India have investigated the causative organisms of VAP. Pseudomonas spp., Acinetobacter spp., Escherichia coli, Klebsiella pneumoniae and Staphylococcus aureus were identified as the common VAP pathogens with varying prevalence. Upto $40 \%$ of these infections can be polymicrobial. Pseudomonas spp., Acinetobacter spp. and even Enterobacteriaceae are quite often multidrug-resistant due to production of extended spectrum beta ( $\beta$ )-lactamases (ESBL), AmpC $\beta$-lactamases (AmpC) or metallo- $\beta$-lactamases (MBL). The aetiological agents of VAP vary with different patient populations and types of ICUs. Therefore, the local microbial flora causing VAP 
needs to be studied in each setting to guide more effective and rational utilisation of antimicrobial agents. ${ }^{4}$

\section{MATERIALS AND METHODS}

This descriptive study with seventy-four non-repetitive endotracheal secretion samples received between April 2016 and April 2017 were processed in Microbiology laboratory, Yenepoya Medical College Hospital Laboratory. According to standardised procedures, we abstracted the following information prospectively from each patient for more than 48 hours under mechanical ventilation: demographic data (age, sex), cause of admission, comorbidities (COPD, CHF and Renal failure) and length of ICU stay period, duration of ventilation therapy, prior antibiotics and occurrence of VAP.

Exclusion criteria were: 1) Pneumonia being the cause of admission, 2) Intubation without mechanical ventilation in ICU, 3) Patients who were suffering from chest trauma.

A clinical criterion for diagnosis of VAP was made by modified clinical pulmonary infection score (CPIS). ${ }^{5}$

\begin{tabular}{|c|c|c|c|}
\hline CPIS Points & 0 & 1 & 2 \\
\hline $\begin{array}{c}\text { Temperature } \\
\left({ }^{\circ} \mathrm{C}\right)\end{array}$ & $\begin{array}{c}\geq 36.5 \text { and } \\
\leq 38.4\end{array}$ & $\geq 38.5$ and $\leq 38.9$ & $\geq 39$ and $\leq 36$ \\
\hline $\begin{array}{c}\text { Leucocyte } \\
\text { count (per } \\
\text { mm3) }\end{array}$ & $\begin{array}{l}4000- \\
11000\end{array}$ & $<4000$ or $>11000$ & $\begin{array}{l}<4000 \text { or }>11000 \\
+ \text { band forms } \geq 500\end{array}$ \\
\hline $\begin{array}{c}\text { Tracheal } \\
\text { secretions }\end{array}$ & Rare & Abundant & Abundant + Purulent \\
\hline $\begin{array}{c}\mathrm{PaO}_{2} / \mathrm{FiO}_{2} \\
\mathrm{~mm} \mathrm{Hg}\end{array}$ & $\begin{array}{c}>240 \text { or } \\
\text { ARDS }\end{array}$ & & \\
\hline $\begin{array}{l}\text { Chest } \\
\text { radiograph }\end{array}$ & $\begin{array}{c}\text { No } \\
\text { infiltrate }\end{array}$ & Diffuse infiltrate & $\begin{array}{l}\leq 240 \text { and no ARDS } \\
\text { Localised infiltrate }\end{array}$ \\
\hline $\begin{array}{l}\text { Culture of } \\
\text { tracheal } \\
\text { aspirate }\end{array}$ & $\begin{array}{l}\text { Light } \\
\text { growth } \\
\text { or no } \\
\text { growth }\end{array}$ & $\begin{array}{l}\text { Moderate or } \\
\text { heavy growth } \\
\text { of pathogenic } \\
\text { bacteria }\end{array}$ & $\begin{array}{c}\text { Moderate or heavy } \\
\text { growth of pathogenic } \\
\text { bacteria and presence } \\
\text { of the same bacteria in } \\
\text { Gram stain }\end{array}$ \\
\hline
\end{tabular}

Establishment of aetiologic diagnosis required isolation of bacteria in significant quantity from a sample of lower respiratory tract secretions $\left(B A L>10^{4} \mathrm{cfu} / \mathrm{mL}\right)$. Only the first episode of documented VAP was taken into account. Acquired specimens by endotracheal aspiration were transferred to the microbiological laboratory immediately. By using a modified two-fold dilution scheme, we determined the quantitative culture in $\mathrm{cfu} / \mathrm{mL}$. The media and incubation conditions were appropriate for the cultivation of the most probable respiratory pathogens. Antimicrobial susceptibility of the clinical isolates to routinely used antibiotics was determined by Kirby-Bauer disk diffusion method.6,7

The organisms isolated by quantitative culture of the endotracheal aspirate (EA) from VAP patients were identified based on standard microbiological techniques. The susceptibility of the clinical isolates to some routinely used antibiotics was determined by the Kirby-Bauer disk diffusion method. Ampicillin (AMP), Amoxy-clav (AMC), piperacillin (PI), ciprofloxacin (CIP), cefepime (CPM), cefotaxime (CTX), ceftazidime (CAZ), levofloxacin (LE), gentamicin (G), amikacin (AK), tetracycline (T), Cotrimoxazole (COT), chloramphenicol (C), piperacillin-tazobactam (PTZ) and meropenem (MR) were tested for Enterobacteriaceae. Similar drugs along with tobramycin (TOB), tigecycline (TGC), colistin (CL) and piperacillin-tazobactam (PTZ) were tested for non-fermenters. Ampicillin, tetracycline (T), erythromycin (E), clindamycin (CD), ciprofloxacin, gentamicin linezolid (LZ), teicoplanin (TEI) and vancomycin (VA) were tested for $\mathrm{S}$. aureus. Methicillin resistance in S. aureus was determined using Cefoxitin (CX) disc 30 g. ${ }^{7}$

Combination disk method using both ceftazidime, alone and in combination with clavulanic acid, was performed for detection of extended spectrum-lactamase (ESBL) among the members of Enterobacteriaceae. Five mm or more increase in zone of inhibition for ceftazidime-clavulanic acid disk compared to the ceftazidime disk was taken as confirmatory evidence of ESBL production. ${ }^{8,9}$

\section{RESULTS}

Out of 74 non-repetitive isolates, the most common isolate was pseudomonas aeruginosa (27\%) followed by Acinetobacter spp. (20.3\%), Klebsiella spp. (16.2\%) and E. coli $(12 \%)$. Among gram positive bacteria in our study, only Staphylococcus aureus (9.5\%) was isolated.

\begin{tabular}{|c|c|c|}
\hline Isolate & Number & \% Isolation \\
\hline Pseudomonas aeruginosa & 20 & 27 \\
\hline Acinetobacter spp. & 15 & 20.3 \\
\hline E. coli & 9 & 12 \\
\hline Klebsiella spp. & 12 & 16.2 \\
\hline Citrobacter spp. & 1 & 1.4 \\
\hline Enterobacter spp. & 3 & 4 \\
\hline P. vulgaris & 1 & 1.4 \\
\hline Staphylococcus aureus & 7 & 9.5 \\
\hline S. maltophilia & 3 & 4 \\
\hline Burkholderia & 1 & 1.4 \\
\hline Sphingomonas & 1 & 1.4 \\
\hline Flavobacter meningosepticum & 1 & 1.4 \\
\hline Total & 74 & \\
\hline \multicolumn{3}{|c|}{$\begin{array}{l}\text { Table 2. Distribution of Isolates } \\
\text { from Endotracheal Aspirates }\end{array}$} \\
\hline
\end{tabular}

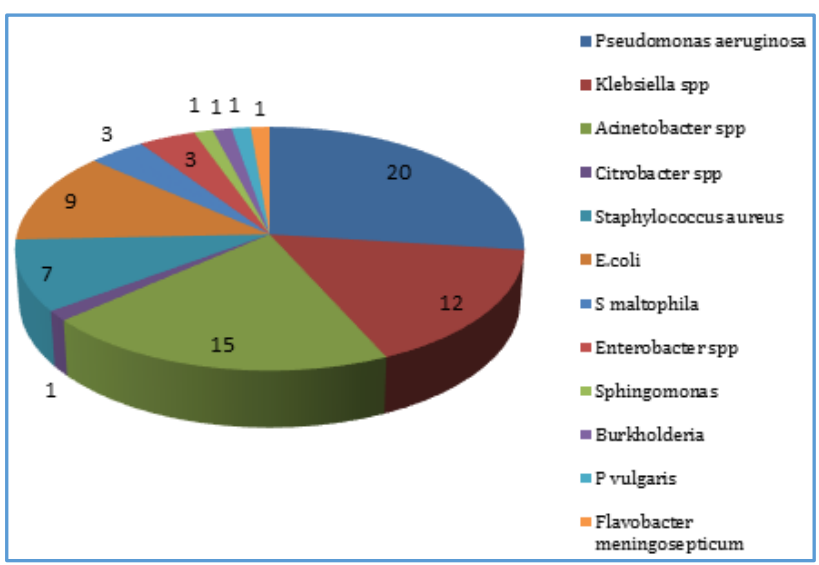

Figure 1. Prevalence of Isolates in CT Culture 


\begin{tabular}{|c|c|c|c|c|c|c|c|c|c|c|c|c|c|c|c|c|}
\hline Isolate & AMP & AMC & PI & CPM & CAZ & CTX & CIP & LE & G & AK & T & COT & C & I & MR & PTZ \\
\hline E. coli & 89 & 44 & 67 & 78 & 67 & 78 & 78 & 11 & 67 & 44 & 44 & 33 & 11 & 33 & 11 & 67 \\
\hline Klebsiella & 100 & 58 & 50 & 75 & 75 & 83 & 67 & 17 & 67 & 5 & 33 & 42 & 42 & 50 & 25 & 58 \\
\hline Proteus & - & 0 & 100 & 0 & 0 & 100 & 100 & 0 & 100 & 0 & - & 100 & 100 & 0 & 100 & 100 \\
\hline Citrobacter & - & 100 & 0 & 0 & 0 & 0 & 0 & 0 & 100 & 0 & - & 0 & 0 & 50 & 0 & 0 \\
\hline Enterobacter & 100 & 100 & 0 & 0 & 0 & 34 & 67 & 0 & 34 & 0 & 100 & 0 & 0 & 50 & 0 & 0 \\
\hline
\end{tabular}

Table 3. Percentage resistance among Enterobacteriaceae

Among enterobacteriaceae high resistance was seen for $\beta$-lactams including cephalosporins for E. coli and Klebsiella (70\% and $73 \%$ respectively), whereas Citrobacter and Enterobacter showed good sensitivity (60\% and $80 \%)$, but Proteus spp. showed varied resistance to these drugs. Ciprofloxacin resistance (64\%) was much higher in enterobacteriaceae members, while good sensitivity was observed with levofloxacin (94\%). Among aminoglycosides only $10 \%$ resistance was noted for amikacin, while $74 \%$ of isolates showed Gentamicin resistance. Meropenem showed a better sensitivity (78\%) pattern as compared with imipenem (64\%) for enterobacteriaceae members.

\begin{tabular}{|c|c|c|c|c|c|c|c|c|c|c|c|c|c|c|c|c|c|}
\hline Isolate & PI & CPM & CAZ & G & AK & TOB & CIP & LE & COT & C & T & I & MR & PTZ & PB & TGC & CL \\
\hline Pseudomonas & 20 & 20 & 30 & 30 & 20 & 0 & 15 & 0 & 40 & - & 40 & 25 & 10 & 15 & 5 & 5 & 5 \\
\hline Acinetobacter & 40 & 67 & 73 & 67 & 60 & 0 & 67 & 0 & 47 & 40 & 40 & 53 & 40 & 53 & 0 & 0 & 0 \\
\hline NFGNB & 67 & 67 & 83 & 33 & 50 & 0 & 50 & 17 & 50 & 67 & 17 & 83 & 17 & 83 & 0 & 0 & 17 \\
\hline
\end{tabular}

Table 4. Percentage resistance among Non-Fermenters

Among the antibiotics used, pseudomonas isolates had a good sensitivity to $\beta$-lactams (PI- 80\%, CPM- $80 \%$ and CAZ$70 \%$ ), among aminoglycosides and quinolones, resistance to Gentamicin, amikacin and ciprofloxacin was low (30\%, 20\% and $15 \%$ ), while all isolates were sensitive to tobramycin and levofloxacin; $10 \%$ of the pseudomonas isolated were potential carbapenemase producers.

Acinetobacter spp. and other non-fermenters had high resistance to routinely used antibiotics like B-lactams (66.6\%) and aminoglycosides (52\%). Among quinolones, sensitivity for levofloxacin (82\%) was better than ciprofloxacin $(42 \%)$.

All non-fermenters showed good sensitivity to higher antibiotics like tobramycin (100\%), polymyxin B (98\%), colistin (96\%) and tigecycline (98\%).

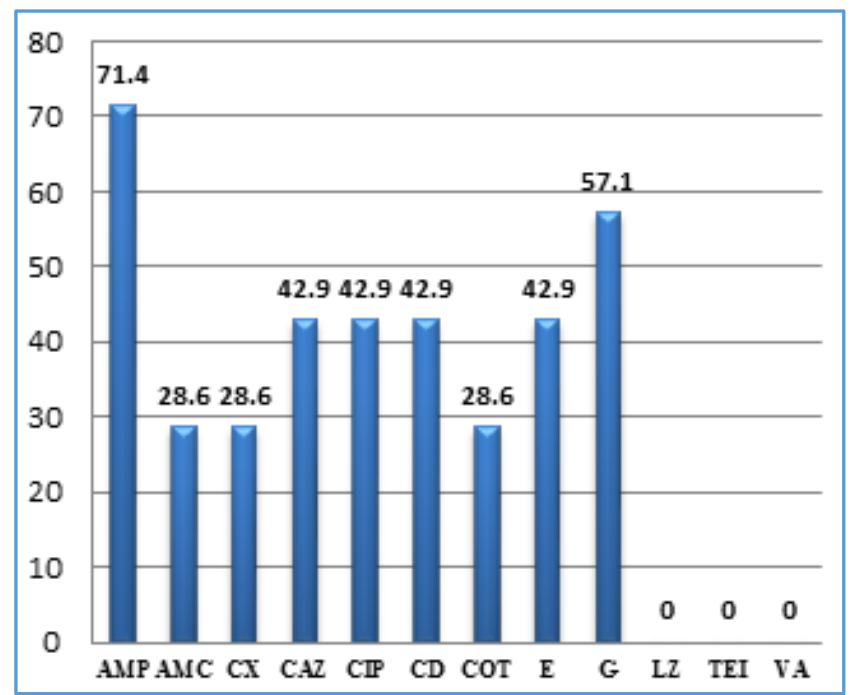

Figure 2. \% Resistance in Staphylococcus aureus

Out of seven Staphylococcus aureus isolates, MRSA was found in $28.6 \%$. All isolates were sensitive to linezolid, teicoplanin and vancomycin. Moderate degree of resistance was found for amoxy-clav (28.6\%), ceftazidime (42.9\%), clindamycin $(42.9 \%)$, ciprofloxacin $(42.9 \%)$, cotrimoxazole
(28.6\%) and erythromycin (42.9\%); however, high resistance was seen in ampicillin (71.4\%) and gentamicin (57.1\%).

\section{DISCUSSION}

VAP is an important nosocomial infection among critically ill patients receiving mechanical ventilation. The clinical diagnosis of VAP can be made using the modified CPIS score. Quantitative cultures of the lower respiratory secretions obtained by endotracheal aspiration (EA) or bronchoscopic techniques such as bronchoalveolar lavage (BAL) are essential for deciding appropriate therapy for the VAP patients. In recent years, various investigators are recommending quantitative analysis of EA as a simple and useful tool for the diagnosis of VAP.

The majority of bacterial isolates in our study were Pseudomonas aeruginosa (27\%) followed by Acinetobacter spp. (20\%) and Klebsiella spp. (16\%). These findings are in concordance with other researchers Mahshid Talebi Taher et $\mathrm{al}^{2}$ found Pseudomonas aeruginosa and Klebsiella pneumonia (50\% each), RM Saldanha Dominic et $\mathrm{al}^{1}$ in their study found a similar order of prevalence. Pseudomonas accounted for $41.14 \%$ followed by Klebsiella species $(15.43 \%)$ and Acinetobacter species $(10.28 \%)$. On the other hand, Ranjit $\mathrm{S}$ and Bhattarai $\mathrm{B}^{10}$ found a higher incidence of Acinetobacter spp. (34\%) followed by Pseudomonas spp. (19\%) and Klebsiella spp. (12\%).

In our study pseudomonas isolates had a good sensitivity to $\beta$-lactams (PI- 80\%, CPM- 80\% and CAZ- 70\%) and resistance to Gentamicin, amikacin and ciprofloxacin was low (30\%, 20\% and 15\%). These findings are in line with the results by RM Saldanha Dominic et al, ${ }^{1}$ who found Pseudomonas to be most sensitive to Amikacin (52.78\%) and Ceftazidime (47.22\%); $10 \%$ of the pseudomonas isolated were potential carbapenemase producers. Kotgire Santosh A and Tankhiwale Nilima ${ }^{11}$ in their study showed that 7 of 20 isolates were carbapenemase producers Acinetobacter spp. and other non-fermenters had high resistance to routinely used antibiotics like B-lactams (66.6\%), aminoglycosides (52\%) and also imipenem (53\%), meropenem (40\%) resistance was moderately high in our study. All nonfermenters showed good sensitivity to higher antibiotics like 
tobramycin (100\%), polymyxin B (98\%), colistin (96\%), tigecycline (98\%). In a study by RM Saldanha Dominic et al, ${ }^{1}$ Acinetobacter was found to be most sensitive to chloramphenicol (50\%) and Amikacin (38.89\%). Kotgire Santosh A and Tankhiwale Nilima ${ }^{11}$ in their study showed a better sensitivity for Acinetobacter spp. Of the 5 Acinetobacter spp., 2 (40\%) were AmpC $\beta$-lactamase producers and they were sensitive to imipenem and meropenem, while no $\mathrm{M} \beta \mathrm{L}$ producers were seen. The remaining isolates were sensitive to aminoglycosides, ciprofloxacin and b-lactams.

We found a high resistance for $\beta$-lactams (70\%) including cephalosporins (73\%), Ciprofloxacin (64\%), Gentamicin (74\%) for E. coli and Klebsiella, while good sensitivity was observed with levofloxacin (94\%) and amikacin (90\%). RM Saldanha Dominic et al $^{1}$ showed that Klebsiella was most sensitive to Amikacin (66.67\%) and Ciprofloxacin (59.26\%). E. coli was most sensitive to Amikacin and Ciprofloxacin ( $50 \%$ each). Kotgire Santosh A and Tankhiwale Nilima ${ }^{11}$ on the other hand found that all the strains of E. coli and $\mathrm{K}$. pneumoniae were sensitive to imipenem, meropenem and piperacillin tazobactam, while the remaining enterobacteriaceae isolates were sensitive to gentamicin, amikacin, ciprofloxacin and ceftazidime. Also, MRSA prevalence in our study was found in $28.6 \%$ isolates. The MRSA prevalence is diverse in various studies; RM Saldanha Dominic et $\mathrm{al}^{1}$ (69.5\%), Ranjit S and Bhattarai $\mathrm{B}^{10}(0 \%)$, Kotgire Santosh A and Tankhiwale Nilima ${ }^{11}$ (53.3\%).

\section{CONCLUSION}

The commonest organism, which was isolated from the ET aspirate cultures were non-fermenting gram-negative bacilli as seen in various studies done in India. Multidrug resistant organisms are increasing. Requirement of mechanical ventilation for more than four days increases the risk. These patients need special attention towards preventive measures. The overall outcome of VAPs could improve with the antimicrobial policies of individual centres. So, in conclusion, the potential MDR in ICU and hospital settings emphasises the judicious use of antimicrobial therapy, so as to decrease the incidence of VAP and the overall morbidity, mortality and the longer stay of patients in the hospital.

\section{REFERENCES}

[1] Dominic RMS, Prashanth HV, Shenoy S, et al. A clinicomicrobiological study of ventilator-associated pneumonia in a tertiary care hospital. Int J Biol Med Res 2012;3(2):1651-4.

[2] Taher MT, Mousavi SAJ, Pour HM. Ventilator associated pneumonia: microbiology and identification of antimicrobial resistance pattern by disk-diffusion and E. test methods. Clinical Infectious Diseases 2008;3(1):13-8.

[3] Alp E, Voss A. Ventilator associated pneumonia and infection control. Ann Clin Microbiol Antimicrob 2006;5:7.

[4] Joseph NM, Sistla S, Dutta TK, et al. Ventilatorassociated pneumonia in a tertiary care hospital in India: role of multi-drug resistant pathogens. J Infect Dev Ctries 2010;4(4):218-25.

[5] Pugin J, Auckenthaler R, Mili N, et al. Diagnosis of ventilator-associated pneumonia by bacteriologic analysis of bronchoscopic and nonbronchoscopic "blind" bronchoalveolar lavage fluid. Am Rev Respir Dis 1991;143(5 Pt 1):1121-9.

[6] Forbes BA, Sahm DF, Weissfeld AS. Bailey \& scotts diagnostic microbiology. $12^{\text {th }}$ edn. Mosby Elsevier, China. 2007.

[7] Winn WC, Allen SD, Janda WM, et al. Koneman's color Atlas and Textbook of Diagnostic Microbiology. $6^{\text {th }}$ edn. Philadelphia. Lippincott Williams \& Wilkins, 2006:1443-71.

[8] Miles RS, Amyes SGB. Laboratory control of antimicrobial therapy. In: Mackie, McCartney (eds). Practical medical microbiology. 14th edn. Elsevier publishers New Delhi, 2006:151-77.

[9] Performance standards for antimicrobial susceptibility testing. 27th edn. M100, 2017.

[10] Ranjit S, Bhattarai B. Incidence and risk factors for ventilator-associated pneumonia in Kathmandu university hospital. Kathmandu University Medical Journal 2011;9(1):28-31.

[11] Santosh AK, Nilima T. Study of multidrug resistant (MDR) isolates in patients with ventilator associated pneumonia in a rural hospital. Journal of Clinical and Diagnostic Research 2011;5(7):1363-6. 